\title{
Types of Urinary Incontinence Prevalent among Kuwaiti Women with Type Two Diabetes Mellitus
}

\section{Sanaa M. Taghaddom1, Florence E. Omu ${ }^{3 *}$, Fawzeyah S. H. S. AlHarbi ${ }^{2}$, Chitra Vellolikalam ${ }^{3}$, Samiha I. A. Dwaib², Selma Joseph², Gifta Jeevakumari ${ }^{2}$}

${ }^{1}$ Nursing Department, Ministry of Health, Kuwait City, Kuwait

${ }^{2}$ Sabah Al Ahmad Urology Centre, Ministry of Health, Kuwait City, Kuwait

${ }^{3}$ College of Nursing, The Public Authority for Applied Education \& Training, Kuwait City, Kuwait

Email:*flo_omu@hotmail.com

How to cite this paper: Taghaddom, S.M., Omu, F.E., AlHarbi, F.S.H.S., Vellolikalam, C., Dwaib, S.I.A., Joseph, S. and Jeevakumari, G. (2017) Types of Urinary Incontinence Prevalent among Kuwaiti Women with Type Two Diabetes Mellitus. Open Journal of Nursing, 7, 1131-1143. https://doi.org/10.4236/ojn.2017.710082

Received: September 14, 2017

Accepted: October 14, 2017

Published: October 17, 2017

Copyright $\odot 2017$ by authors and Scientific Research Publishing Inc. This work is licensed under the Creative Commons Attribution International License (CC BY 4.0).

http://creativecommons.org/licenses/by/4.0/

\begin{abstract}
The aim of this study was to determine the types of urinary incontinence prevalent among Kuwaiti women with Type two Diabetes Mellitus attending the outpatient clinic at the Urology center and suggest appropriate nursing interventions. Urinary incontinence is not a life threatening condition but it can be emotionally devastating and therefore affects the sufferer's quality of life. This cross-sectional descriptive survey consisted of 250 Kuwaiti women with type two diabetes mellitus receiving treatment at the outpatient department at Sabah Al-Ahmad Urology Center, Kuwait. The questionnaire comprised of a total of 33 questions, twelve of which explored participants' socio demographic characteristics, risk factors and symptoms of their urinary incontinence. The remaining 21 items were adapted from King's Health Questionnaire (KHQ) formulated in 1997 at King's college, London, for the assessment of quality of life in women with urinary incontinence. Data collection was from February to May 2014. The result revealed that mixed urinary incontinence was the most prevalent type of urinary incontinence affecting Kuwaiti women with type two diabetes mellitus. Symptoms of both stress incontinence and urge incontinence (Over active bladder) were not mutually exclusive as they were present in 247 (98.8\%) and 240 (96\%) of the participants respectively. Key risk factors for developing incontinence were over three years duration of diabetes mellitus in 115 (56\%) and delivery of one or more children reported by 206 (82\%) of the participants. Analysis and result of King Health Questionnaire on quality of life will be reported in separate paper on the psychosocial impact of urinary incontinence on diabetic Kuwaiti women. In conclusion, urinary incontinence had a devastating effect on the lives of sufferers
\end{abstract}


and therefore should be prevented at all cost by nurses providing anticipatory guidance to all pregnant and diabetic women and routinely teaching pelvic floor exercises to all postnatal women. However, in the event that there are symptoms of urinary incontinence then thorough investigation and early treatment is advocated.

\section{Keywords}

Urinary Bladder Dysfunction, Stress Incontinence, Urge Incontinence, Overactive Bladder, Mixed Incontinence, Type Two Diabetes Mellitus

\section{Introduction}

A change in voiding pattern is one of the most common reasons for people to consult urologists. The International Continence Society defines Urinary Incontinence (UI) as "involuntary loss of urine that is a hygienic or social problem to the individual" [1] [2]. UI was classified as "any reported leaking of urine once or more than once per month" while frequent urinary incontinence is "once and more leaking of urine per week" [3]. UI can be emotionally devastating although it is not a life threatening condition. It is usually a symptom of an underlying condition that ultimately affects the sufferer's quality of life and therefore needs to be investigated and treated [2]. UI is most often perceived as a chronic condition commonly affecting elderly people, however, some studies have shown that it is not limited to age or gender, it affects the young adults, males and females [4] [5]. Other conditions with risk factors for UI included neurological conditions like stroke, Parkinson's disease, multiple sclerosis, diabetes mellitus, cardiovascular, and pulmonary disorders [4] [5].

Another classification of UI is according to the symptoms exhibited by the sufferer, which include: stress incontinence, urge incontinence also referred to as over active bladder $(\mathrm{OAB})$, mixed incontinence which is a combination of the previous two types, unspecified urinary incontinence, functional urinary incontinence, total incontinence, nonorganic enuresis, and urinary incontinence associated with cognitive impairment [3] [6] [7] [8] [9]. The three common types of $\mathrm{UI}$ affecting women are stress urinary incontinence, urge incontinence/OAB and mixed incontinence. Of these three, stress incontinence is most common in women over the age of 30 with the prevalence rate of $24 \%$ to $45 \%$ in middle age women and $50 \%$ in older women [10]. International Continence Society defined stress incontinence as "the observation of involuntary leakage from the urethra, synchronous with exertion, sneezing or coughing" [2]. The leakage of urine therefore is associated with weakness of the pelvic floor muscles, weakness of the urethral sphincter and activities that cause increase intra-abdominal pressure or increase pressure in the pelvic region including: exercise, coughing, sneezing, laughing hard, lifting heavy objects, sexual intercourse, bending down, standing up and getting out of a car. The risk factors for its development include pelvic 
floor surgery, pregnancy and childbirth. The second most common type of UI in women is urge incontinence/OAB as a result of over activity of the detrusor muscles. Common reactions specific to urge incontinence/OAB are frequency, urgency, and nocturia [7]. The third type is the mixed incontinence, which is the presence of both stress incontinence and urge incontinence/OAB in the individual.

The emotional impact of urinary incontinence in woman include embarrassment, depression, social and recreational isolation from fear or anxiety related to being incontinent in public, especially for individuals with urge incontinence/ $\mathrm{OAB}$ because they cannot predict the time leakage will occur from over activity of the detrusor muscles. These psychosocial reactions inevitably affect the sufferer's quality of life [2] [11].

Diabetes Mellitus (DM) has been reported as a key risk factor for developing UI [5]. Urinary frequency is one of the reactions of type two DM and it is one of the main common reactions present in urge incontinence/OAB. To clearly differentiate the symptoms of urge incontinence/OAB from urinary symptoms associated with type two DM, it may be necessary to perform urodynamic studies [7]. Diabetic bladder dysfunction has been reported as a spectrum of urge incontinence/OAB and its prevalence was reported to be from $25 \%$ to $87 \%$ [9]. In 2006, The World Health Organization (WHO) estimated the prevalence of type two diabetes mellitus among adult females in Kuwait as 11.5\% [12]. In 2013, The Dasman Diabetic Institute reported their findings of a retrospective cohort study involving 270,172 subjects gathered from nationwide database from Kuwait Health Network. This database collates all the health records from all primary health clinics and hospitals in Kuwait. The crude prevalence rate of type two diabetes mellitus was reported as $33.25 \%$ of Kuwaitis and $25.4 \%$ of expatriates [13].

UI is one of the oldest challenges in nursing care of hospitalized clients. Literature search using CINAHL and MEDLINE databases revealed numerous studies exploring nursing strategies for improving the care of hospitalized incontinent clients [14]. Researchers are now investigating the prevalence of UI in individuals not hospitalized, to identify their risk factors, health and psychosocial consequences [2] [7] [11].

Although there are limited studies on the prevalence and risk factors for UI in diabetic women in the Middle East region/Arab countries, the literature review in this study will focus on these studies because of similarities in culture, religion and way of life to Kuwaiti women. The prevalence, risk factors and impact on quality of life on women with UI in Qatar were investigated by Ghafouri and his colleagues [15]. Five hundred and twenty-one women participated in phase one of the study and 1,086 women participated in the second phase. The participants were women above 18 years attending primary health centers and outpatient clinics at Hamad General Hospital in Qatar. The data collection tool for Quality of Life was the International Consultation Incontinence Questionnaire-Short form (ICIQ-SF). The prevalence rate of UI was 108 (20.7\%). Bronchial asthma 
was a co-morbidity reported in the women. In terms of Quality of Life, 79\% of them expressed moderate to severe negative impact on their quality of life [15]. Bani-Issa with different researchers conducted studies in Jordan and United Arab Emirate [16] [17] [18]. Their study on the prevalence of UI and its perceived psychosocial impact on 1,011 Jordanian women aged 20 to 65 years attending primary healthcare centers was conducted in Jordan using a standardized incontinence questionnaire. The findings revealed that $435(43 \%)$ were diabetic and 576 (57\%) were non-diabetic women, and a total of $676(66.8 \%)$ of the women reported symptoms of UI. The prevalence of urge and stress incontinence was significantly higher in diabetic than in non-diabetic women. The Jordanian women with UI felt it had negative impact on their psychosocial well-being [16]. Bani-Issa's first Emirati study [17] was a cross-sectional survey of 300 Emirati women aged 20 to 65 years with type two DM, attending six healthcare centers in the United Arab Emirate. They investigated for the prevalence, risk factors for UI and its impact on their wellbeing using standardized incontinence questionnaire. The findings were that 188 (63\%) suffered from some degree of UI: 154 (51.3\%) had stress incontinence while 181 (60.3\%) had urge incontinence. Duration of DM was the significant risk factors for both stress and urge incontinence. Age was reported to be a risk factor for stress incontinence, while Body Mass Index (BMI) was a risk factor for urge incontinence. Regarding the emotional aspects of their incontinence, the women reported that incontinence as cumbersome, disrupting both their social and religious activities [17]. A year later, Bani-Issa and his colleagues [18] reported the findings of another study comprising of 350 Emirati women with DM using a different research tool: the National Health and Nutrition Examination Survey-Kidney Condition-Urology. Two hundred and twenty five (64.3\%) participants had UI. The findings were that stress incontinence and urge incontinence symptoms were present in 197 (56.3\%) and 208 (59.4\%) respectively. In this study, the co-morbidity was type 2 diabetes mellitus and the duration of diabetes was the most significant risk factor for incontinence [18]. A Bahrani study [19], investigated the risk factors in 259 women receiving treatment for UI at the Urogynecologic clinic, at Salmaniya Medical complex, Bahrain, Their findings revealed the following risk factors for UI: recurrent urinary tract infection 34\%, chronic constipation 32\%, DM 17.4\%, spinal diseases 14.3\%, gastrointestinal diseases $12 \%$, neurological diseases $2 \%$, bronchial asthma and chronic obstructive pulmonary disease $4.6 \%$ and the remaining $17 \%$ were on diuretics [19]. Two studies were reported from Saudi Arabia: Al-Badr and his colleagues [20], investigated the prevalence of urinary incontinence in 379 Saudi women attending Ministry of Health Primary Health Care center in Jeddah. They reported an overall prevalence of UI to be $41.4 \%$. The risk factors for UI included age, parity, history of vaginal gynecologic surgery, chronic cough and constipation. Surprisingly, $85.5 \%$ of these women did not seek medical treatment for UI despite reporting adverse effect on their activities of daily living [20]. The second Saudi Arabian study was conducted as a clinic-based cross-sectional survey of 6,600 
women in Saudi Arabia resident in Riyadh [21], using the Arabic version of Urogenital Distress Inventory (UDI-6) and the Incontinence Impact Questionnaire (IIQ-7). Their findings revealed that the overall prevalence of UI was $29 \%$, Stress incontinence was $50 \%$, urge incontinence was $28 \%$ and mixed incontinence was $22 \%$. The most significant risk factor for UI in their study was DM. Other risk factors included older age, obesity, large baby birth weight, high parity, caesarean delivery and vaginal delivery and like the other Saudi women in Jeddah, most of the affected women did not seek medical care [21]. Al-Sayegh and colleagues [4] reported their study on UI in Kuwait, prevalence and risk factors for men and women. Their study was a cross-sectional survey using a convenient sample consisting of 268 women and 152 men, recruited from four shopping malls, primary health care facilities and General hospitals in Kuwait. Their findings revealed that $146(54.5 \%)$ of the women and $34(22.4 \%)$ of the men had UI. The risk factors for the women included age, parity, and vaginal delivery, BMI of over $25 \mathrm{~kg} / \mathrm{m}^{2}$, and history of DM. Only twenty two women (15\%) and two men (5.8\%) sought medical care for their UI. The reason given by those who did not seek medical care was lack of awareness that UI was a problem requiring medical attention [4].

\section{Methodology}

\subsection{Study Setting}

This study was conducted at Sabah Al Ahmed Urology Center, Kuwait. This tertiary health care center was opened $4^{\text {th }}$ February 2013. The center treats children, adults, males and females with urology problems. It is a 97 bedded hospital with a daily urology outpatient clinic. The center is fully equipped with advance facilities for diagnostic, preventive and curative urology care.

\subsection{Objective}

The objective of the study was to determine the types and risk factors for UI among diabetic Kuwaiti women, aged 20 to 65 years. The study will therefore tested the following null hypotheses:

$\mathrm{H}_{0} 1$ : There is no difference in the factors that activate stress incontinence and urge incontinence in Kuwaiti diabetic women.

$\mathrm{H}_{0}$ 2: There is no association between urinary incontinence and body mass index.

$\mathrm{H}_{0}$ 3: There is no difference in the severityl frequency of urine leakage experienced among the different age groups of Kuwaiti women with type two diabetes mellitus.

\subsection{Data Collection Tools}

The questionnaire was developed in two sections: section A: consisted of 12 questions exploring participants' socio demographic characteristics, risk factors and symptoms of their urinary incontinence. Section B: consisted of questions 
adapted from King's Health Questionnaire (KHQ) formulated in 1997 at King's college, London, for the assessment of quality of life in women with urinary incontinence. KHQ consisted of 21 items exploring nine domains: general health perception, incontinence impact, role limitations, physical limitations, social limitations, personal relationships, emotions, sleep/energy and severity measures [5]. The questions were in 5-point likert scale. The questionnaire was first translated into Arabic and back translated into English and final questionnaire was in Arabic, the official language in Kuwait.

\subsection{Pilot Testing}

Both the English and Arabic questionnaires were pilot tested with 25 patients and ambiguous questions were rephrased for clarity.

\subsubsection{Participants}

The participants consisted of a convenient sample of 250 Kuwaiti women with type two diabetes mellitus receiving treatment for different types of urinary bladder dysfunction at the Outpatient department at Sabah Al-Ahmad Urology Center, Kuwait. The sample size was based on selecting all the women who met the inclusion criteria during the period of data collection from February to May 2014.

Inclusion criteria: Kuwaiti women with urinary dysfunction and type two diabetes mellitus, aged between 20 to 65 years and willing to participate in the study.

Exclusion criteria: Non-Kuwaiti women, Kuwaiti women younger than 20 years or older than 65 years, non-diabetic Kuwaiti women, Kuwaiti women with mental health challenges and patients not willing to participate.

\subsubsection{Ethical Considerations}

Permission to conduct the study was sort and obtained from the Institutional Ethical committee.

An Arabic research assistant explained the nature and purpose of the study to each participant. They were told that participation was voluntary and questionnaires were anonymous and non-participation will not affect their treatment. Signed consent was obtained and questionnaires were distributed to willing participants.

\subsubsection{Data Collection}

The Arabic research assistants distributed the questionnaires to willing participants and were available to answer questions and collect the completed questionnaires.

\subsubsection{Data Analysis}

Data was analyzed using the Statistical Package for Social Sciences (SPSS) version 24 for Windows. Frequencies and percentages were used to describe demographic data. Frequency of urine leak was the dependent variable. Inferential 
statistics were analyzed using non-parametric Pearson's chi-square test and $\mathrm{P}$ values of 0.05 were considered statistically significance.

\section{Results}

\subsection{Demographic Characteristics of Participants}

Two hundred and fifty Kuwaiti diabetic women participated in the study. The age distribution of participants ranged from 20 to 65 years. Participants aged 20 to 35 years were $64(26 \%)$; 36 to 50 years were $98(39 \%)$; while 51 to 65 years were $88(35 \%)$. The majority of the women, 201 (80\%) were married, $28(11 \%)$ were single and 21 (8\%) were divorced. One hundred and sixty (64\%) were employed while 90 (36\%) were either house wives or they were not employment.

\subsection{Types of UI Prevalent among Kuwaiti Women with Type Two DM}

Table 1 describes frequency and severity of urine leak. Leaking urine several times a day was reported by 59 (23.6\%) women, those leaking once daily were 36 (14.4\%), leakage frequency of 2 - 3 times per week were 59 (23.6\%); those with occasional leaks $\geq 1$ per month were $93(37.2 \%)$ and those with occasional leaks of less than monthly were $3(1.2 \%)$.

Table 2 describes the factors activating stress incontinence.

The symptoms of both stress incontinence and urge incontinence/OAB reported were not mutually exclusive as some participants reported more than one symptom of either one or both types of incontinence, making mixed urinary incontinence the predominant type. Two hundred and forty seven (98.8\%) of the women report symptoms of stress incontinence while 240 (96\%) of the participants reported at least one symptom of urge incontinence/OAB. Among those with symptoms of stress incontinence 94 (38\%) of them mentioned coughing and sneezing as responsible for their urine leak, laughing in 47 (19\%), lifting objects in $57(23 \%)$, exercise in $31(12.4 \%)$ and the least cause of urine leak was bending down reported by 18 (7.2\%).

Table 1. Frequency and severity of urine leak by age group (N250).

\begin{tabular}{|c|c|c|c|c|c|c|}
\hline Age group & $\begin{array}{c}\text { Several } \\
\text { times/day }\end{array}$ & Once/day & $\begin{array}{c}2-3 \\
\text { times/week }\end{array}$ & $\begin{array}{c}\text { Occasionally } \\
\geq \text { once/month }\end{array}$ & $\begin{array}{c}\text { Occasionally } \\
<\text { monthly }\end{array}$ & Total \\
\hline & Number (\%) & Number (\%) & Number (\%) & Number (\%) & Number (\%) & Number (\%) \\
\hline $\begin{array}{c}20-35 \\
\text { years }\end{array}$ & $6(2.4)$ & $14(5.6)$ & $5(2.0)$ & $36(14.4)$ & $3(1.2)$ & $64(25.6)$ \\
\hline $\begin{array}{c}36-50 \\
\text { years }\end{array}$ & $22(8.8)$ & $10(4.0)$ & $26(10.4)$ & $40(16.0)$ & 0 & $98(39.2)$ \\
\hline \multirow[t]{2}{*}{$\begin{array}{c}51-65 \\
\text { years }\end{array}$} & $31(12.4)$ & $12(4.8)$ & $27(10.8)$ & $18(7.2)$ & 0 & $88(35.2)$ \\
\hline & $59(23.6)$ & $36(14.4)$ & $58(23.2)$ & $94(37.6)$ & $3(1.2)$ & $250(100)$ \\
\hline
\end{tabular}


Table 2. Factors that Activated Stress incontinence (N247).

\begin{tabular}{ccc}
\hline Factors Activating urine leak & Number & $\%$ \\
\hline Coughing or sneezing & 94 & 38.06 \\
Lifting & 57 & 23.07 \\
Laughing & 47 & 19.02 \\
Exercise & 31 & 12.55 \\
Bending down & 18 & 7.28 \\
Total & 247 & 100 \\
\hline
\end{tabular}

\subsection{Testing Null Hypotheses}

$\mathrm{H}_{0} 1$ : There is no difference in the factors activating stress incontinence and urge incontinence in Kuwaiti diabetic women.

The participants that reported symptoms of stress incontinence had significant Pearson's chi square results for factors that activate leaking of urine which included coughing and sneezing $\left(\chi^{2}=12.534, \mathrm{df}=3, \mathrm{p}<0.006\right)$, laughing $\left(\chi^{2}=\right.$ 36.903, $\mathrm{df}=3, \mathrm{p}<0.000)$ and lifting heavy objects $\left(\chi^{2}=14.206, \mathrm{df}=3, \mathrm{p}<\right.$ $0.003)$. Among the participants that reported at least one symptom of urge incontinence/OAB: 86 (34.4\%) reported experiencing sudden strong urge to urinate, $62(28.8 \%)$ said they rush to the bathroom to urinate, 48 (19.2\%) leak urine while undressing to use the toilet, 31 (12.4\%) loss urine in sudden large amount while $38(15.2 \%)$ wake up more than once at night to urinate. Pearson's chi-square was significant for experiencing sudden strong urge to urinate $\left(\chi^{2}=\right.$ 16.791, $\mathrm{df}=3, \mathrm{p}<0.001)$ and leaking urine while undressing to use the toilet was significant, $\left(\chi^{2}=32.243, \mathrm{df}=3, \mathrm{p}<0.000\right)$. The P-values were significant, so the null hypothesis is rejected. It implies that different factors activate stress and urge incontinence in diabetic women.

$\mathrm{H}_{0} 2$ : There is no association between urinary incontinence and body mass index.

Body Mass Index ranged from underweight to obesity. Only $40 \%$ of the participants were over-weight and obese. The breakdown is as follows: $3(1.2 \%)$ of the participants were under-weight $<20 \mathrm{~kg} / \mathrm{m}^{2}, 147(58.8 \%)$ were within normal range $20-25 \mathrm{~kg} / \mathrm{m}^{2}, 81$ (32.4\%) were over-weight $26-30 \mathrm{~kg} / \mathrm{m}^{2}$, and the remaining $19(7.6 \%)$ were obese, $>31 \mathrm{~kg} / \mathrm{m}^{2}$. However, Pearson's chi-square was significant for frequency of leak with BMI $\left(\chi^{2}=17.912, \mathrm{df}=9, \mathrm{p}<0.036\right)$. The $\mathrm{P}$-values were significant, so the null hypothesis is rejected. It implies that BMI is associated with UI.

$\mathrm{H}_{0} 3$ : There is no difference in the severityl frequency of urine leakage experienced among the different age groups of Kuwaiti women with type two diabetes mellitus.

Table 1 illustrates age group as a risk factor for developing UI. The most severe urine leakers were participants aged 36 - 65 years. They reported urine leakage daily, either several times or at least once per day. The Pearson chi-square 
was used in testing this hypothesis. The result indicated that there was statistical difference in the frequency of urinary incontinence among the different age group $\left(\chi^{2}=38.877\right.$, df $\left.6, \mathrm{p}<0.000\right)$. The $\mathrm{p}$-values were significant; it therefore implies that the null hypothesis is rejected. This means that age group is associated with UI.

\subsection{Other Risk Factors for UI Included History of Childbirth and Duration of DM}

Childbirth was reported by 206 (82\%) of the women. Out of the 206 women with history of childbirth, 71 (28\%) were primiparous while 135 (54\%) were multiparous. Their types of delivery ranged from normal vaginal delivery 106 (42.4\%), complicated vaginal delivery 63 (25.2\%), cesarean section delivery $56(22.4 \%)$ and $1(0.4 \%)$ multiparous woman had both normal delivery and cesarean section delivery. Pearson's chi-square was significant for frequency of leak with type of delivery was significant $\left(\chi^{2}=24.882, \mathrm{df}=12, \mathrm{p}<0.016\right)$. The duration of DM reported by participants were: $<1$ year, 74 (29.6\%), 1 - 3 years, $82(32.8 \%)$ and $>3$ years $94(37.6 \%)$. Pearson's chi-square was significant for frequency of leak with duration of diabetes mellitus $\left(\chi^{2}=41.205, \mathrm{df}=6, \mathrm{p}<0.000\right)$.

\section{Discussion}

\subsection{Prevalence of UI in Kuwaiti Women with DM}

The objective of this study was to determine the types and risk factors for UI among Kuwaiti women with type two DM. UI was defined as "leaking of urine $\geq$ once per month" [3]; this definition was used in coding the responses of incontinency in this study. Although, there are many international studies published on UI among diabetic women [3] [6] [7] [8] [9], only a few studies have been published on prevalence of UI in diabetic women in the Middle East/Arabic countries [16] [17] [18]. Most of the studies published on urinary incontinence in the Middle East/Arabic countries were directed to a broader population of women not necessarily with diabetic co-morbidity [4] [19] [20] [21]. This study focused on only incontinent Kuwaiti women with type two DM. The findings of studies on UI in diabetic women showed a higher prevalence of UI in the diabetic women when compared to their non-diabetic counterparts [6] [7] [8] [9] [3]. Bani-Issa and colleagues [17] reported that the prevalence of UI was higher in diabetic Emirati women than in other cultures, suffice to say that they did not have any data from Kuwait for comparison. The findings from this study showed extremely higher prevalence rate in Kuwaiti diabetic women than in the Emirati diabetic women. Mixed incontinence was the most prevalent type of UI occurring in 238 (95.2\%) of our participants. Furthermore, studies with diabetic and non-diabetic participants also reported higher prevalence of urinary incontinence with diabetic than non-diabetic women [18]. The co-morbidity of type two diabetes mellitus in all our participants might have contributed to their having such high prevalence of stress incontinence and urge incontinence/OAB. 
Diabetic bladder dysfunction has been classified as a spectrum of $\mathrm{OAB}$ and its prevalence was reported to be from $25 \%$ to $87 \%$ [9]. The duration of DM in our participants was reported as $<1$ year, 74 (29.6\%), 1 - 3 years, $82(32.8 \%)$ and $>3$ years $94(37.6 \%)$. Pearson's chi-square was significant for frequency of leak with duration of Diabetes mellitus $\left(\chi^{2}=41.205, \mathrm{df}=6, \mathrm{p}<0.000\right)$.

\subsection{Risk Factors for the Development of Urinary Incontinence}

Our third null hypothesis was to test if there was a significant difference in the age group in the development of urinary incontinence. The Pearson chi-square result indicated that there was statistical difference in the frequency of urinary incontinence among the older age groups $\left(\chi^{2}=38.877, \mathrm{df}=6, \mathrm{p}<0.000\right)$. Higher age group being a risk factor for developing incontinence was reported by many researchers [4] [16] [18] [19] [20] [21]. History of childbirth, have been implicated as a key risk factor for urinary incontinence. Out of the $206(82 \%)$ incontinent diabetic Kuwaiti women with history of childbirth, 135 (54\%) were multiparous compared to 71 (28\%) who were primiparous. Their types of delivery ranged from normal vaginal delivery 106 (42.4\%), complicated vaginal delivery $63(25.2 \%)$, cesarean section delivery $56(22.4 \%)$ and $1(0.4 \%)$ multiparous woman had both normal delivery and cesarean section delivery. Similar findings were reported in most of the studies reviewed [4] [18] [20] [21]. BMI was a significant risk factor for urinary incontinence found in our study. Body Mass Index ranged from underweight, $<20 \mathrm{~kg} / \mathrm{m}^{2}$ were $74(29.6 \%)$, normal from 20 to 25 $\mathrm{kg} / \mathrm{m}^{2}$ were $147(58.8 \%)$, overweight from 26 to $30 \mathrm{~kg} / \mathrm{m}^{2}$ were $81(32.4 \%)$ to obesity $>31 \mathrm{~kg} / \mathrm{m}^{2}$ were $19(7.6 \%)$. Pearson's chi-square was significant for frequency of leak with BMI $\left(\chi^{2}=17.912, \mathrm{df}=9, \mathrm{p}<0.036\right)$. This finding was similar to those in the literature we reviewed [4] [18] [19] [20] [21].

\subsection{Impact of Urinary Incontinence on Participant's Perceived Quality of Life}

Sinclair and Ramsey [2] reported emotional impact of incontinence to include social and recreational isolation from anxiety and fear of being incontinent in public. When our participants were asked to evaluate the extent UI had affected their lives, 129 (52\%) of them felt they were either not affected at all or it only had a little impact on their quality of life. The findings of an earlier study in Kuwait [4]; were comparable with our study as $75 \%$ of their female participants said they did not perceive their urinary incontinence as a health challenge and therefore did not seek medical care [4]. Reports from other Arab countries were contradictory to the Kuwaiti findings; the Qatari study reported that $79 \%$ of his Qatari women participants reported moderate to severe negative impact on their lives [15]. The Jordanian women felt it had a negative impact on their psychosocial well-being [16], and the Emirati women felt urinary incontinence was cumbersome, disrupting their social and religious activities [18]. The Saudi women in both Jeddah and Riyadh reported adverse effect on their lives yet majority of them did not seek medical care [20] [21]. 


\subsection{Nursing Implications}

Nurses are the largest members of the health care professionals, and they have the unique opportunity to identify clients at risk of urinary incontinence. Midwives and obstetric nurses should provide anticipatory guidance and health teaching to all pregnant women regarding incontinence preventive measures after delivery. They should co-ordinate with the physiotherapy departments to teach Kegel/pelvic floor muscle exercises during antenatal and postnatal period to all mothers. Leaflets on how to perform pelvic floor exercises should be distribute to all postnatal women before discharge. They should also display posters and leaflets in polyclinics and outpatient depart of hospital to provide awareness of the symptoms of urinary incontinence and how to prevent it as a result of childbirth. Secondly, gynecologic nurses should teach Kegel exercises as pre-operative preparation for their clients needing surgery in the pelvis. Thirdly, diabetic nurses should also provide health teaching to their clients on early detection of signs of urinary incontinence and provide anticipatory guidance on prevention and early treatment.

\section{Limitations \& Recommendations}

Self-administered questionnaire was the data collection tool for the study. The inclusion of urodynamic parameters would have enhanced the researchers to clearly differentiate the participants with overactive bladder from those with diabetic bladder dysfunction.

A multi-disciplinary team approach involving diabetic team, dieticians, the physiotherapist, psychologist and urology nurses should be introduced as part of the management of incontinent women with type two DM.

\section{Conclusion}

Symptoms of stress incontinence and urge incontinence/OAB were present in 98\% and $96 \%$ of the participants respectively. Risk factors included childbirth, duration of DM, older age group and high BMI. The $\mathrm{p}$ values of the groups according to the risk factors were $0.016,0.000,0.000$ and 0.036 respectively. Urinary incontinence had a negative impact on the sufferers' quality of life. The relevance of our study to clinical practice is that nurses should provide anticipatory guidance to all pregnant and diabetic women and routinely teach pelvic floor exercises to all postnatal women.

\section{Acknowledgements}

The authors sincerely thank the following people for their guidance and support throughout the study: Dr. Fawzi Abul, Hospital Director for Sabah Al-Ahmad Urology center, Mrs. Samaa Mohammed, Assistant Nursing Director, SDU, Mrs. Mary Kurian, Dr. Hoda Diab and Dr. Ali Sadek, Statistician at Kuwait Ministry of Health, for his assistance with statistical analysis. 


\section{Funding and Conflict of Interest Statements}

No funding or grant was received for this study and no conflict of interest declared.

\section{References}

[1] Stöppler, M.C. and Davis, C.P. (2015) Urinary Incontinence. Medicinehealth.com.

[2] Sinclair, A.J. and Ramsay, I.N. (2011) The Psychosocial Impact of Urinary Incontinence in Women. The Obstetrician \& Gynaecologist, 13, 143-148. https://doi.org/10.1576/toag.13.3.143.27665

[3] Devore, E.E., Townsend, M.K., Resnick, N.M. and Grodstein, F. (2012) The Epidemiology of Urinary Incontinence in Women with Type 2 Diabetes. The Journal of Urology, 188, 1816-1821. https://doi.org/10.1016/j.juro.2012.07.027

[4] Al-Sayegh, N.A., Al-Batool, L., Al-Qallaf, A., Al-Fadhli, H. and Al-Sharrah, S. (2014) Urinary Incontinence in Kuwait: Prevalence and Risk Factors of Men and Women. International Journal of Health Sciences, 2, 47-57. https://doi.org/10.15640/ijhs.v2n4a4

[5] Hebbar, S., Pandey, H. and Chawlah, A.C. (2015) Understanding King's Health Questionnaire (KHQ) in Assessment of Female Urinary Incontinence. International Journal of Research in Medical Sciences, 3, 531-538. https://doi.org/10.5455/2320-6012.ijrms20150301

[6] Phelan, S., Kanaya, A., Ma, Y., Vittinghoff, E., Barrett-Connor, E., Wing, R., Kusek, J., Orchard, T.J., Cranball, J.P., Montez, M.G. and Brown, J.S. (2015) Long-Term Prevalence and Predictors of Urinary Incontinence among Women in the Diabetes Prevention Program Outcome Studies. International Journal of Urology, 22, 206-212.

[7] Karoli, R., Bhat, S., Fatima, J. and Priya, S. (2014) A Study of Bladder Dysfunction in Women with Type 2 Diabetes Mellitus. Indian Journal of Endocrinology and Metabolism, 18, 552-557. http://www.ijem.in/text.asp?2014/18/4/552/137518 https://doi.org/10.4103/2230-8210.137518

[8] Jahromi, M.K., Ramezani, S., Taheri, L. and Rahmanian, A. (2014) Management of Stress Urinary Incontinence in Females with Diabetes Mellitus (Type 2). Journal of Diabetes and Metabolism, 5, 351.

[9] Golbidi, S. and Laher, I. (2010) Bladder Dysfunction in Diabetes Mellitus. Frontiers in Pharmacology, 1. https://doi.org/10.3389/fphar.2010.00136

[10] Hunskaar, S., Arnold, E.P., Burgio, K., Diokno, A.C., Herzog, A.R. and Mallett, V. T. (2000) Epidemiology and Natural History of Urinary Incontinence. International Urogynecology Journal, 11, 301-319. https://doi.org/10.1007/s001920070021

[11] Khandelwal, C. and Kistler, C. (2013) Diagnosis of Urinary Incontinence. American Family Physician, 87, 543-550. http://www.aafp.org/afp/2013/0415/p543.html

[12] World Health Organization (2006) Diabetes in the Eastern Mediterranean Region. http://www.emro.who.int/ncd/pdf/Diabetes

[13] Channanath, A.M., Farran, B., Behbehani, K. and Thanaraj, T.A. (2013) State of Diabetes, Hypertension, and Comorbidity in Kuwait: Showcasing the Trends as Seen in Native versus Expatriate Populations. Diabetic Care, 36, e75.

[14] Blanchette, K.A. (2012) Exploration of Nursing Care Strategies for the Management of Urinary Incontinence in Hospitalized Women. Urologic Nursing, 32, 256-259. 
[15] Ghafouri, A., Alnaini, A.R., Alhothi, H.M., Alroubi, I., Alrayyashi, M., Molhim, N.A. and Shokeir, A.A. (2014) Urinary Incontinence in Qatar: A Study of the Prevalence, Risk Factors and Impact on Quality of Life. Arab Journal of Urology, 12, 269-274. https://doi.org/10.1016/j.aju.2014.08.002

[16] Bani-Issa, W., Almomani, F. and Eldeirawi, K. (2013) Urinary Incontinence among Adult Women with Diabetes in Jordan: Epidemiology, Correlates and Perceived Impact on Emotional and Social Well-Being. Journal of Clinical Nursing, 23, 2451-2460. https://doi.org/10.1111/jocn.12392

[17] Bani-Issa, W., Fakhry, R. and AlMomani, F. (2013) Urinary Incontinence in Emirati Women with Diabetes Mellitus Type 2: Prevalence, Risk Factors and Impact on Life. Journal of Clinical Nursing, 22, 3084-3094. https://doi.org/10.1111/jocn.12176

[18] Bani-issa, W. A., Halabi, J. O., Abdullah, A.R., Hassan, H.A. and Raigangar, V. (2014) Prevalence and Risk Factors for Incontinence Among Emirati Women with Diabetes. Journal of Transculture Nursing, 1, 42-50.

https://doi.org/10.1177/1043659613503873

[19] Al-Jufairi, Z.A., Gherbal, W.H. and Al-Najjar, F.S. (2014) Risk Factors of Urinary Incontinence in Bahrain. International Journal of Gynecology \& Clinical Practices, $1,105$.

[20] Al-Badr, A., Brasha, H., Al-Raddadi, R., Noorwali, F. and Ross, S. (2012) Prevalence of Urinary incontinence among Saudi Women. International Journal of Gynecology \& Obstetrics, 117, 160-163. https://doi.org/10.1016/j.ijgo.2011.12.014

[21] Altaweel, W. and Alharbi, M. (2012) Urinary Incontinence, Prevalence, Risk Factors and Impact on Health Related Quality of Life in Saudi Women. Neurourology and Urodynamics, 31, 642-645. https://doi.org/10.1002/nau.22201 